\title{
Pulse Wave Velocity Comparing Estimated and Direct Measures of Path Length in Older Women
}

\author{
Ludovica Bognoni ${ }^{1,2, t,(\mathbb{D}) \text {, Marina Cecelja }}{ }^{1, *, \dagger}$, Tarique Hussain ${ }^{3,4,(\mathbb{D}}$, Gerald Greil ${ }^{3,4}$, Tim Spector ${ }^{3}$, Philip Chowienczyk ${ }^{1}$, \\ J. Kennedy Cruickshank ${ }^{5}$ \\ ${ }^{1}$ King's College London British Heart Foundation Centre, Cardiovascular Division, Department of Clinical Pharmacology, St Thomas' Hospital, London, UK \\ ${ }^{2}$ University of Medicine, Università Vita-Salute San Raffaele, Milan, Italy \\ ${ }^{3}$ King's College London, Department of Twin Research and Genetic Epidemiology, St Thomas' Hospital, London, UK \\ ${ }^{4}$ Department of Pediatrics, UT Southwestern Medical Center, Dallas, Texas \\ ${ }^{5}$ School of Lifecourse \& Nutritional Sciences, King's College, London and Clinical Research Facility, Guy's and St Thomas' Hospitals, London, UK
}

\section{ARTICLE INFO}

Article History

Received 22 March 2020

Accepted 04 August 2020

Keywords

Pulse wave velocity

tonometry

hypertension

arterial stiffness

cardiovascular morbidity

cardiovascular mortality

TwinsUK

\begin{abstract}
Background: Carotid-femoral Pulse Wave Velocity (cfPWV) is the gold-standard measure of arterial stiffness. Accuracy of non-invasive cfPWV as meters per second is impeded by surface estimates of aortic length. Our aim was to compare cfPWV measured using distance estimated from surface measurements with distance traced along the length of the aorta using Magnetic Resonance Imaging (MRI) in a cohort of older women.
\end{abstract}

Methods: Seventy-four women were recruited from the TwinsUK cohort. cfPWV was measured using the SphygmoCor system (SphygmoCor-PWV). The path between carotid and femoral sites was estimated from surface measurements between the sternal notch and femoral artery applanation point. Aortic distance was measured with MRI to obtain MRI-PWV. cfPWV was recalculated using MRI obtained distance.

Results: Mean \pm standard deviation SphygmoCor-PWV was $9.9 \pm 2.1 \mathrm{~m} / \mathrm{s}$ and MRI-PWV $7.63 \pm 1.97 \mathrm{~m} / \mathrm{s}$ (mean difference $2.2 \pm 1.96 \mathrm{~m} / \mathrm{s}, p<0.001)$. Distances were considerably higher using surface measures for the SphygmoCor $(55.2 \pm 3.0,95 \%$ confidence interval $54.4-55.9 \mathrm{~cm})$ compared with MRI $(39.9 \pm 3.2,39.2-40.7 \mathrm{~cm})$ with a mean difference of $15.2 \mathrm{~cm}(14.3-16.2 \mathrm{~cm}$, $p<0.001)$. Transit times were also marginally longer with the SphygmoCor. When SphygmoCor-PWV was Recalculated using MRI-obtained aortic distance (rec-PWV), the difference between SphygmoCor-PWV and rec-PWV reduced to $0.5 \mathrm{~m} / \mathrm{s}(7.13 \pm$ 1.46 vs. $7.63 \pm 1.97 \mathrm{~m} / \mathrm{s}, p=0.08)$.

Conclusion: In these older women, the PWV difference between SphygmoCor and MRI is substantial but reduced when using MRI length estimates. Important differences between PWV measured by Sphygmocor and MRI are mainly due to accuracy of distance measurements, which may need re-addressing in guidelines.

(c) 2020 Association for Research into Arterial Structure and Physiology. Publishing services by Atlantis Press International B.V. This is an open access article distributed under the CC BY-NC 4.0 license (http://creativecommons.org/licenses/by-nc/4.0/).

\section{INTRODUCTION}

Pulse Wave Velocity (PWV) as a measure of arterial stiffness powerfully predicts cardiovascular morbidity and mortality, independently of Blood Pressure (BP) and other standard risk factors [1,2]. A meta-analysis of 16 different studies relating aortic PWV to mortality and cardiovascular outcomes clearly showed that, independent of simultaneous blood pressure, aortic PWV enables better identification of high-risk populations who should benefit from more aggressive risk factor management [3].

Although the gold standard for PWV measurement is invasive cardiac catheterization from the ascending aorta to the bifurcation

"Corresponding author. Email: marina.3.cecelja@kcl.ac.uk

${ }^{\dagger}$ Co-first author.

Peer review under responsibility of the Association for Research into Arterial Structure and Physiology

Data availability statement: Data in this study are available upon request through application to the TwinsUK data access committee. Information on data access and how to apply is available at http://www.twinsuk.ac.uk/dataaccess/submission-procedure/.
[4], Carotid-femoral PWV (cfPWV) obtained with non-invasive tonometry is a reasonable surrogate for daily clinical practice [5].

Magnetic Resonance Imaging (MRI)-PWV also correlates well with invasive measurements, as PWV measurement by MR and pressure catheters agree well, that is within 2 Standard Deviation (SD) of each technique's values [6].

Pulse wave velocity is more commonly measured between the carotid and femoral arterial sites acquired non-invasively by tonometry, using the SphygmoCor System (Sphygmocor-PWV; Atcor Medical, West Ryde, Australia). cfPWV is calculated by dividing the difference in distance between the carotid and femoral arteries by the difference in transit time referenced to the QRS complex of the Electrocardiogram (ECG). However, accuracy of non-invasive cfPWV is impeded by imprecise aortic length measurements, which is overestimated in older adults when aortic tortuosity and length are increased $[7,8]$. In older men we found the length error using the body surface averaged as much as $7 \mathrm{~cm}$ compared with MRI length [9]. 
Although correlation is not the same as measure of agreement [10], PWV by tonometry and MRI correlate well, but with a significant and consistent bias, SphygmoCor-PWV being about $1.6-1.7 \mathrm{~m} / \mathrm{s}$ higher than MRI-PWV [11]. To compensate for this bias, current guidelines suggest multiplying tonometrically acquired cfPWV by 0.8 [12]. The current consensus formula was determined by analysing relevant literature in different study populations. However older women were not specifically considered in those analyses. - see Table 1 which summarises previous literature. The aims of this study were to compare: (a) the differences in SphygmoCor and MRI calculated PWV in a cohort of older women; (b) cfPWV recalculated using MRI aortic distance.

\section{MATERIALS AND METHODS}

Participants were recruited from the TwinsUK cohort including both dizygotic and monozygotic female twins [17]. Seventyfour study participants aged 51-80 years completed the protocol undergoing cfPWV measurement both by SphygmoCor and MRI. Demographic data were obtained by questionnaire. The study was authorised by St. Thomas' Hospital Research Ethics Committee. Written informed consent was collected for each volunteer.

\subsection{Hemodynamic Measurements}

Vascular characteristics were obtained during a single visit for both SphygmoCor and MRI measures. Participants were asked not to eat, drink caffeine or smoke for at least $3 \mathrm{~h}$ before the examination, as per guidelines [9]. Blood pressure and heart rate were measured in triplicate using an oscillometric device validated for tonometry (Omron $705 \mathrm{CP}$, Omron, Tokyo, Japan) in a quiet vascular laboratory at St. Thomas' Hospital with the subject in supine position before proceeding to SphygmoCor evaluation. The mean value of the last two readings was used as the estimated BP. Mean Arterial Pressure (MAP) was estimated from the peripheral Systolic Blood Pressure (SBP) and peripheral Diastolic Blood Pressure (DBP) as

$$
\mathrm{MAP}=\frac{\mathrm{SBP}+(2 * \mathrm{DBP})}{3}
$$

\subsection{Pulse Wave Velocity Measured Using Sphygmocor}

Carotid-femoral PWV was measured by ECG-referenced sequential tonometry of the carotid and femoral arteries using the SphygmoCor system (Atcor Medical). During SphygmoCor measurements participants were asked to lie supine and a three lead I ECG electrodes were attached on the chest and an appropriatelysized BP cuff was adjusted over the brachial artery. SphygmoCor aortic length was estimated from the body surface using a tape measure for the distance between the sternal notch and the femoral artery applanation point, as previously described [18]. Carotid and femoral pressure pulse was recorded using applanation tonometry and the time differences between the ECG $R$ wave to carotid pulse recording and between the ECG $\mathrm{R}$ wave to femoral pulse were calculated and taken as the transit times.

Table 1 Summary of previous literature

\begin{tabular}{|c|c|c|c|c|}
\hline Study & Methods & Cohort & Age & Results \\
\hline $\begin{array}{l}\text { Huybrechts et al. [13] } \\
\text { Carotid-femoral Pulse Wave Velocity } \\
\text { (cfPWV): comparison of real } \\
\text { travelled aortic path length by } \\
\text { Magnetic Resonance Imaging } \\
\text { (MRI) and superficial measures }\end{array}$ & $\begin{array}{l}\text { Carotid-femoral path lengths by MRI } \\
\text { y compared with } 11 \text { estimates of aortic } \\
\text { path length from body surface } \\
\text { distances, from tape measures or } \\
\text { body height }\end{array}$ & 98 healthy men/women & $\begin{array}{r}21-76 \\
\text { years }\end{array}$ & $\begin{array}{l}\text { Real travelled aortic path length } \\
\text { may be estimated by multiplying } \\
\text { surface measurements by } 0.8\end{array}$ \\
\hline $\begin{array}{l}\text { Weber et al. [14] } \\
\text { Noninvasive cfPWV depends } \\
\text { critically on assessment of travel } \\
\text { distance: a comparison with inva- } \\
\text { sive measures }\end{array}$ & $\begin{array}{l}\text { PWV was measured during cardiac } \\
\text { catheterization and with the } \\
\text { SphygmoCor, estimating travelled } \\
\text { distance from body surface with } \\
\text { five different methods }\end{array}$ & $\begin{array}{l}135 \text { hospitalised } \\
\text { patients }\end{array}$ & Unspecified & $\begin{array}{l}\text { Surface body measure that best } \\
\text { correlated with invasive distance } \\
\text { was subtracting carotid-supra- } \\
\text { sternal notch from suprasternal } \\
\text { notch-femoral distance }\end{array}$ \\
\hline $\begin{array}{l}\text { Weir-McCall et al. [11] } \\
\text { Effects of inaccuracies in arterial } \\
\text { path length on differences in MRI } \\
\text { and tonometry measured PWV }\end{array}$ & $\begin{array}{l}\text { cfPWV by SphygmoCor; and external } \\
\text { distance by tape measure. True intra- } \\
\text { arterial pathlength via whole body } \\
\text { Magnetic Resonance Angiography } \\
\text { (MRA), used to re-calculate } \\
\text { Sphygmocor cfPWV }\end{array}$ & $\begin{array}{l}114 \text { participants in } \\
\text { the multicentre } \\
\text { SUMMIT study }\end{array}$ & $\begin{array}{l}\text { Not } \\
\text { specified }\end{array}$ & $\begin{array}{l}\text { Differences in cfPWV and } \\
\text { MRI-PWV are due to inaccurate } \\
\text { simple surface measures for the } \\
\text { convoluted carotid-femoral path }\end{array}$ \\
\hline $\begin{array}{l}\text { Rezai et al. [15] } \\
\text { Ethnic differences in aortic PWV } \\
\text { in the descending aorta may be } \\
\text { related to vitamin D }\end{array}$ & $\begin{array}{l}\text { The Arteriograph device used for aortic } \\
\text { PWV, surface measures from sternal } \\
\text { notch to pubis. MRI used to measure } \\
\text { total and segmental aortic length }\end{array}$ & $\begin{array}{l}198 \text { men of African } \\
\text { Caribbean, south } \\
\text { Asian and European } \\
\text { origin }\end{array}$ & $\begin{array}{r}40-80 \\
\text { years }\end{array}$ & $\begin{array}{l}\text { Comparing MR-measured total } \\
\text { aortic length to surface measures } \\
\text { allowed the prediction of } \\
\text { MR-measured total aortic lengths, } \\
\text { from which a regression model } \\
\text { was derived from age and height }\end{array}$ \\
\hline $\begin{array}{l}\text { Weir-McCall et al. [16] } \\
\text { Development and Validation of a } \\
\text { path length calculation for cfPWV } \\
\text { measurement: a TASCFORCE, } \\
\text { SUMMIT and Caerphilly } \\
\text { collaborative venture }\end{array}$ & $\begin{array}{l}\text { All PWV measurements were } \\
\text { performed using a SphygmoCor } \\
\text { device, using a 4-point distance } \\
\text { technique. Whole Body MRA was } \\
\text { used to obtain a direct calculation of } \\
\text { the arterial path length in a sub-sample }\end{array}$ & $\begin{array}{l}1528 \text { study participants } \\
\text { previously in the } \\
\text { TASCFORCE study; } \\
128 \text { re-measured by } \\
\text { MRA }\end{array}$ & $\begin{array}{c}\text { Not } \\
\text { specified }\end{array}$ & $\begin{array}{l}\text { On backward linear regression, age, } \\
\text { sex, heart rate, height and weight } \\
\text { were the strongest predictors of } \\
\text { arterial path length }\end{array}$ \\
\hline
\end{tabular}


Carotid-femoral PWV was then determined by dividing by the surface measured distance by the transit time. For each study participant, the cfPWV was measured in triplicate and the average of the obtained values was used for our analysis. The position of the tonometer was optimized to obtain consistent stable consecutive waveforms of near maximal amplitude. Waveforms that did not pass the quality control of the SphygmoCor system were repeated.

\subsection{Pulse Wave Velocity Measured Using MRI}

From MRI views, the distance from aortic root to bifurcation was traced along the whole imaged aortic length: phase-contrast MRI was performed at the level of the aortic arch and distal to the aortic bifurcation to obtain aortic flow. From a blood-suppressed (blackblood) MRI sequence, aortic distance was traced as the centre of the aorta. Multi-planar reconstruction was then used to trace the length of the aorta and measure aortic distance (Figure 1).

A retrospectively VCG-gated gradient-echo pulse sequence with velocity encoding was applied to measure through-plane flow. This sequence was performed free-breathing and imaging parameters included: echo time $2.9 \mathrm{~ms}$, repetition time $5 \mathrm{~ms}$, slice thickness $8 \mathrm{~mm}$; acquired resolution $2.2 \times 2.2 \mathrm{~mm} ; 2-3$ signal averages; 125 cardiac phases and temporal resolution 5-8 ms. Pulse-wave transit time was recorded according to a previously validated method [19]. In brief, the transit time was defined as the time delay for the arrival of the foot of the pulse wave between measurement points. Arrival of the foot of the pulse wave was calculated using the method of intersecting tangents using automated mathematical waveform detection (Matlab release 2009b, version 7.9 was used to identify the inflection point to center the tangent and each tangent was visually verified by the investigators). Quality Control was provided during acquisition to review for image aliasing, velocity phase wrapping and motion artefacts. Any such detected errors resulted in exclusion and repetition of image acquisition. Two independent observers reviewed images quality and velocity curve profiles prior to terminating the MRI study.

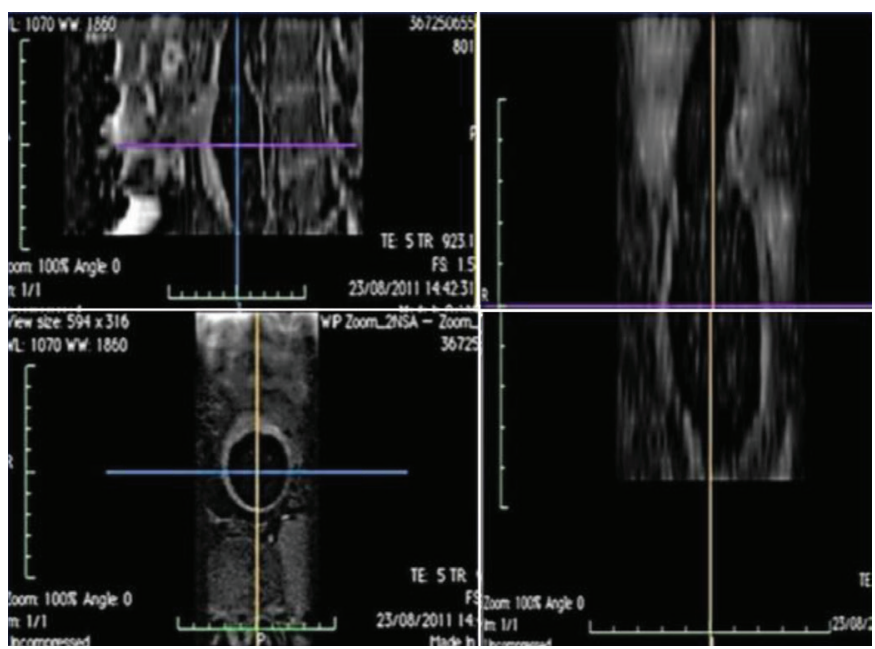

Figure 1 Example of a multiplanar reconstruction used to measure aortic distance. First image on the left: transverse section. Second image on the left: axial section. Image on the right: longitudinal section.

\subsection{Statistical Analysis}

Data analysis was performed with SPSS version 25.0 (SPSS Inc., Chicago, IL, USA). Participant characteristics are presented as mean \pm standard deviation, unless otherwise stated. cfPWV was Recalculated by dividing MRI-obtained aortic length by the transit time from the SphygmoCor measurements (rec-PWV). Student paired $t$-tests were used to assess for statistical differences between the MRI-PWV and rec-PWV, with $p$-values $<0.05$ taken as statistically significant.

\section{RESULTS}

Participant characteristics are shown in Table 2. Average age of participants was $64.7 \pm 7.9$ years. Among the 74 participants, $53(71.6 \%)$ were post-menopausal and seven (9.4\%) were current smokers. Additionally, $22(29.7 \%)$ participants were on anti-hypertensive medications and 18 (24.3\%) were on lipid lowering therapies.

The mean cfPWV obtained through SphygmoCor (SphygmoCorPWV) was $9.87 \pm 2.08 \mathrm{~m} / \mathrm{s}$, while the mean PWV obtained through MRI (MRI-PWV) was $7.63 \pm 1.97 \mathrm{~m} / \mathrm{s}$. Distance measurements were considerably higher using surface measures for the SphygmoCor $(55.1 \pm 3.3 \mathrm{~cm}$; $95 \%$ confidence intervals $54.4-$ $55.9 \mathrm{~cm})$ compared with MRI $(39.9 \pm 3.2 \mathrm{~cm}, 39.19-40.66 \mathrm{~cm})$ with a mean difference of $15.2 \mathrm{~cm}(14.3-16.2 \mathrm{~cm}, p<0.001)$. Transit time using applanation tonometry between the carotid and femoral artery with SphygmoCor $(57.9 \pm 10.7 \mathrm{~ms})$ was marginally higher compared with transit time over the aorta using MRI $(54.9 \pm 11.7 \mathrm{~ms})$ with a mean difference of $2.9 \pm 9.1(1.0-2.1 \mathrm{~ms}$, $p=0.07)$. When we recalculated SphygmoCor-PWV using its transit time and the MRI path length (rec-PWV), the mean rec-PWV was reduced to $7.13 \pm 1.46 \mathrm{~m} / \mathrm{s}$. The difference between rec-PWV and MRI-PWV was $0.49 \mathrm{~m} / \mathrm{s}(0.13-0.85 \mathrm{~m} / \mathrm{s}, p=0.08$, Table 3 and Figure 2). MRI and SphygmoCor-obtained transit time show a linear correlation with a correlation coefficient of $0.67(p=0.67)$, while MRI and SphygmoCor distance measurements correlate

Table 2 Participants characteristics. Mean \pm SD, or N (\%)

\begin{tabular}{lc}
\hline Age (years) & $64.7 \pm 7.9$ \\
Height $(\mathrm{cm})$ & $161.4 \pm 5.9$ \\
Weight $(\mathrm{kg})$ & $65.7 \pm 9.9$ \\
Peripheral systolic blood pressure (mmHg) & $129.7 \pm 16.6$ \\
Peripheral diastolic blood pressure (mmHg) & $74.4 \pm 10.1$ \\
Mean arterial pressure (mmHg) & $95.1 \pm 11.4$ \\
Post-menopausal status & $53 / 74(71.6 \%)$ \\
Current smoker & $7 / 74(9.4 \%)$ \\
Diabetes & $0 / 74(0.0 \%)$ \\
Anti-hypertensive medications & $22 / 74(29.7 \%)$ \\
Lipid lowering therapies & $18 / 74(24.3 \%)$ \\
\hline
\end{tabular}

Table 3 Vascular measurements by Sphygmocor and Magnetic Resonance Imaging (MRI). Mean \pm SD

\begin{tabular}{lccc}
\hline & $\begin{array}{c}\text { Sphygmocor } \\
\text { measurements }\end{array}$ & $\begin{array}{c}\text { MRI } \\
\text { measurements }\end{array}$ & $\boldsymbol{p}$ \\
\hline Transit time (ms) & $57.88 \pm 10.68$ & $54.93 \pm 11.73$ & 0.07 \\
Distance (mm) & $551.64 \pm 33.01$ & $399.32 \pm 32.09$ & $<0.001$ \\
Pulse wave velocity (m/s) & $9.87 \pm 2.08$ & $7.63 \pm 1.97$ & $<0.001$ \\
\hline
\end{tabular}


poorly among one another with a correlation coefficient of 0.19 $(i=0.19)$. As MRI is likely superior, the poor correlation between MRI and SphygmoCor distance measurements is ascribed to the lower quality of travel distance estimations from body surface measurements. This also impacts on the correlation between MRI and SphygmoCor-PWV, which have a correlation coeffiecient of $0.51(\rho=0.51)$, that is indeed intermediate between distance and transit time correlation coefficients. The related scatterplots are represented in Figure 3.

\section{DISCUSSION}

Our main finding is that SphygmoCor-PWV and MRI-PWV differ between each other by about $2 \mathrm{~m} / \mathrm{s}$. However, when using

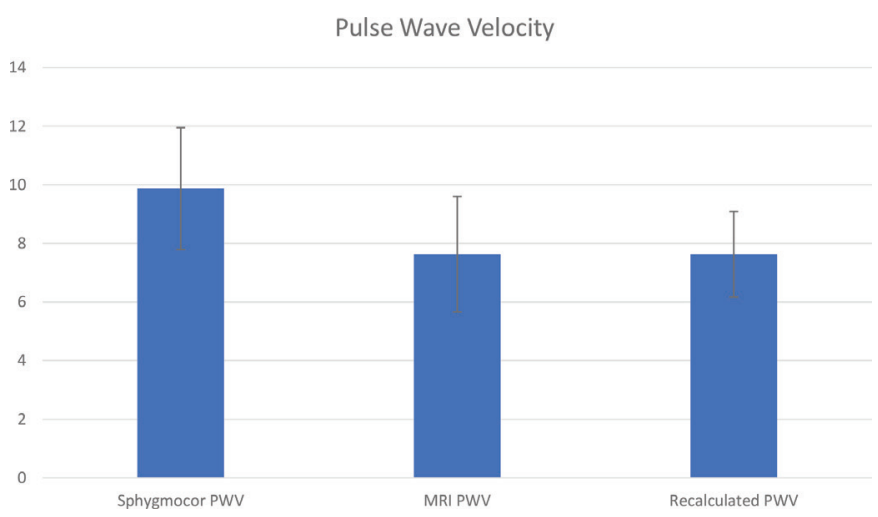

Figure $2 X$-axis: Sphygmocor-PWV, MRI-PWV and rec-PWV. $Y$-axis: numerical values of each PWV. All measures are expressed in $\mathrm{m} / \mathrm{s}$.

a Transit time: SphygmoCor vs MRI

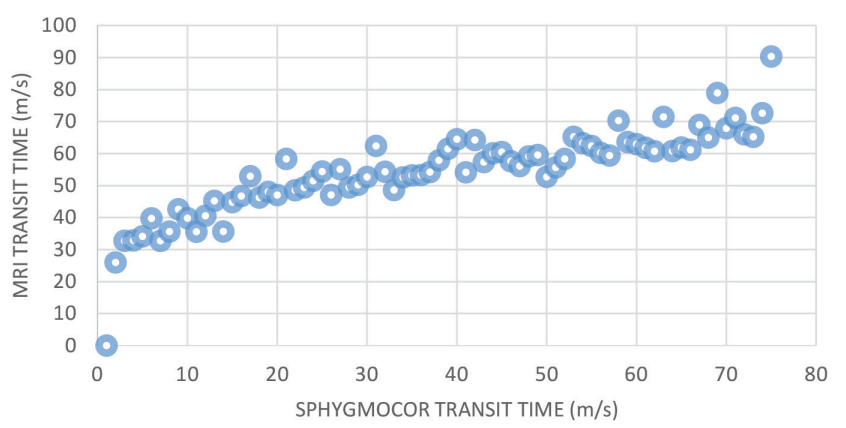

MRI path length to recalculate SphygmoCor-obtained cfPWV the difference between the two diminishes substantially.

Pulse wave velocity measurement may be influenced by either inaccuracy in transit time evaluation or inaccuracy in path length estimation. In this regard, distance estimation from surface measurements may introduce systematic bias as it is impossible to obtain the precise length of the convoluted arterial tree from body surface meaurements. With age this error may increase as the descending aorta increases in tortuosity [8]. The same may happen in obese patients, where a protruding abdomen may contribute to distance overestimation. On the other hand, the opposite is also valid, and distance may be underestimated in people with low BMI and/or of short stature. The above explains some of the difficulties encountered by operators trying to estimate cfPWV non-invasively and shows that misestimations should be mostly attributed to errors in calculating arterial distance from the body surface. Our findings are consistent with previous findings by Weir-McCall et al. [11] who also showed that when SphygmoCor cfPWV was recalculated using the inter-arterial distance obtained from whole body MRI, the difference was less if still significant (mean difference $=-0.96 \pm 2.52 \mathrm{~m} / \mathrm{s}, p=0.001$ ) compared with the MRIPWV. Their patient sample with MRI measured lengths from their 'SUMMIT' cohort $(n=128)$; while larger than ours, that was a mix of men (65\%) and women, with a large proportion (61\%) with type 2 diabetes. The difference between MRI-PWV and SphygmoCor-PWV is also due to including the aortic arch within MRI distance measurements, which are not considered during body surface measurements, a major contributor to path length mis-estimations.

In order to avoid invasive calculations of PWV, the current joint Artery and European Hypertension Societies' guidelines [12] suggest readjusting cfPWV measured using applanation tonometry and surface measurements by a factor of 0.8 . This guidance can only be

b Distance: SphygmoCor vs MRI

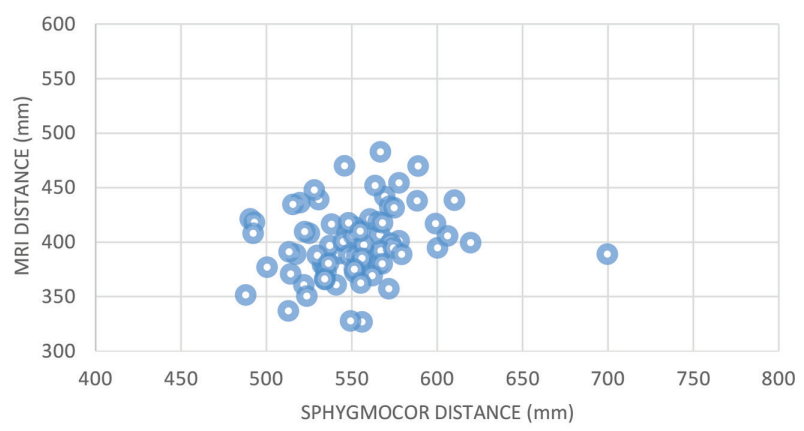

c

PWV: SphygmoCor vs MRI

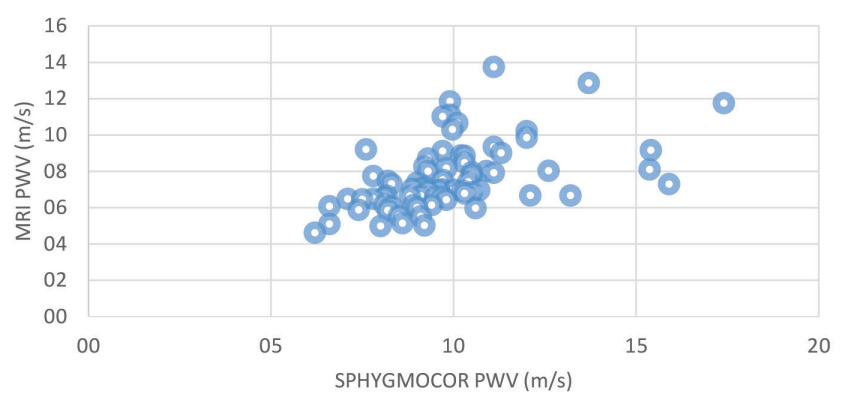

Figure 3 Scatterplots comparing MRI and SphygmoCor obtained transit time [(a), $\rho=0.67]$, distance [(b), $\rho=0.19]$ and PWV [(c), $\rho=0.51]$, respectively. 
applied when body surface distance measurements are obtained as a straight line from the carotid artery to the femoral artery. In our study, to account for the loss of aortic arch length, the distance was instead calculated as an oblique line spanning from the sternal notch to the femoral artery at the point of applanation. For this reason, we were not able to recalculate the SphygmoCor-PWV as suggested.

\subsection{Study Strengths}

To the best of our knowledge, these are the first differences in PWV measurements tested in women over 50 years (as in Table 1). This adds to the literature by showing that previous findings are also valid in a women-only cohort. Moreover, differently from previous studies, we obtained MRI path length through detailed black-blood sequences which provide extremely accurate measurements of in vivo aortic length $[11,16]$. In addition study operators were blinded to either MRI or SphygmoCor measurements, to avoid introduction of operator-dependent bias.

\subsection{Study Limitations}

The study is limited to female participant of the TwinsUK. However, the results are likely to be representative of women in the general population, as characteristics and CVD risk profiles of the TwinsUK cohort are similar to that of the general population $[16,17]$. We also acknowledge that in calibration studies such as this, differences in ambient distending pressures between Sphygmocor and MRI become important, meaning that even small BP changes will affect PWV. Moreover, transit time measurements may introduce bias into the study, as MRI transit time is calculated according to flow-based measurements while SphygmoCor transit time is estimated from the ECG $R-R$ interval. A recent guide to PWV measurement emphasised the time resolution issue over the relatively short length of the aortic arch [20]. However, we submit that because here the two only differ between one another by about $3 \mathrm{~ms}$ (mean difference of $2.96 \pm 9.06 \mathrm{~ms} ; p=0.01$ ), despite that statistical significance, the resulting calculation bias for clinical measurement may be neglected.

\section{CONCLUSION}

In these older women, the cfPWV difference between SphygmoCor and MRI is reduced when MRI length estimates are used. The difference between PWV measured by SphygmoCor and MRI is primarily due to the inaccuracy of surface distance measurements.

\section{CONFLICTS OF INTEREST}

The authors declare they have no conflicts of interest.

\section{AUTHORS' CONTRIBUTION}

MC, LB, PC and JKC contributed in study conceptualization and writing. MC, LB, PC and JKC contributed in review and editing of the manuscript. MC, LB, GG and TH contributed in data curation, formal analysis and writing. LB contributed in original draft. PC and TS contributed in funding acquisition and project. MC contributed in administration. JKC contributed in project supervisor.

\section{FUNDING}

- TwinsUK is funded by the Wellcome Trust, Medical Research Council, European Union, National Institute for Health Research (NIHR)-funded BioResource, Clinical Research Facility and Biomedical Research Centre based at Guy's and St Thomas' NHS Foundation Trust in partnership with King's College London.

- Ludovica Bognoni received funding from the European Union as an Erasmus + Scholarship.

\section{REFERENCES}

[1] Mitchell GF, Hwang SJ, Vasan RS, Larson MG, Pencina MJ, Hamburg NM, et al. Arterial stiffness and cardiovascular events: the Framingham Heart Study. Circulation 2010;121:505-11.

[2] Zhong Q, Hu MJ, Cui YJ, Liang L, Zhou MM, Yang YW, et al. Carotid-femoral pulse wave velocity in prediction of cardiovascular events and mortality: an updated systematic review and meta-analysis. Angiology 2018;69:617-29.

[3] Ben-Shlomo Y, Spears M, Boustred C, May M, Anderson SG, Benjamin EJ, et al. Aortic pulse wave velocity improves cardiovascular event prediction: an individual participant meta-analysis of prospective observational data from 17,635 subjects. J Am Coll Cardiol 2014;63:636-46.

[4] Weber T, Wassertheurer S, Hametner B, Parragh S, Eber B. Noninvasive methods to assess pulse wave velocity: comparison with the invasive gold standard and relationship with organ damage. J Hypertens 2015;33:1023-31.

[5] Weber T, Hametner B, Mayer CC, Wassertheurer S, Boutouyrie P. Invasive validation of devices to measure pulse wave velocity. 2019

[6] Bolster BD, Atalar E, Hardy CJ, McVeigh ER. Accuracy of arterial pulse-wave velocity measurement using MR. J Magn Reson Imaging 1998;8:878-88.

[7] Adriaans BP, Heuts S, Gerretsen S, Cheriex EC, Vos R, Natour E, et al. Aortic elongation part I: the normal aortic ageing process. Heart 2018;104:1772-7.

[8] Tawfik AM, Sobh DM, Gadelhak B, Sobh HM, Batouty NM. The effect of age and gender on tortuosity of the descending thoracic aorta. Eur J Radiol 2019;110:54-9.

[9] Rezai MR, Cowan BR, Sherrat N, Finn JD, Wu FCW, Cruickshank JK. A magnetic resonance perspective of the pulse wave transit time by the Arteriograph device and potential for improving aortic length estimation for central pulse wave velocity. Blood Press Monit 2013;18:111-18.

[10] Bland JM, Altman DG. Statistical methods for assessing agreement between two methods of clinical measurement. Lancet 1986;1:307-10.

[11] Weir-McCall JR, Khan F, Cassidy DB, Thakur A, Summersgill J, Matthew SZ, et al. Effects of inaccuracies in arterial path length measurement on differences in MRI and tonometry measured pulse wave velocity. BMC Cardiovasc Disord 2017;17:118.

[12] Van Bortel LM, Laurent S, Boutouyrie P, Chowienczyk P, Cruickshank JK, De Backer T, et al. Expert consensus document 
on the measurement of aortic stiffness in daily practice using carotid-femoral pulse wave velocity. J Hypertens 2012;30:445-8.

[13] Huybrechts SAM, Devos DG, Vermeersch SJ, Mahieu D, Achten E, de backer TLM, et al. Carotid to femoral pulse wave velocity: a comparison of real travelled aortic path lengths determined by MRI and superficial measurements. J Hypertens 2011;29:1577-82.

[14] Weber T, Ammer M, Rammer A, Adji A, O’Rourke MF, Wassertheurer S, et al. Noninvasive determination of carotidfemoral pulse wave velocity depends critically on assessment of travel distance: a comparison with invasive measurement. J Hypertens 2009;27:1624-30.

[15] Rezai MR, Wallace AM, Sattar N, Finn JD, Wu FCW, Cruickshank JK. Ethnic differences in aortic pulse wave velocity occur in the descending aorta and may be related to vitamin D. Hypertension 2011;58:247-53.

[16] Weir-McCall JR, Brown L, Summersgill J, Talarczyk P, BonniciMallia M, Chin SC, et al. Development and validation of a path length calculation for carotid-femoral pulse wave velocity measurement: a TASCFORCE, SUMMIT and Caerphilly collaborative venture. Hypertension 2018;71:937-45.

[17] Moayyeri A, Hammond CJ, Hart DJ, Spector TD. The UK adult twin registry (TwinsUK Resource). Twin Res Hum Genet 2013;16:144-9.

[18] Cecelja M, Jiang B, Spector TD, Chowienczyk P. Progression of central pulse pressure over 1 decade of aging and its reversal by nitroglycerin: a twin study. J Am Coll Cardiol 2012;59: $475-83$.

[19] Grotenhuis HB, Westenberg JJM, Steendijk P, van der Geest RJ, Ottenkamp J, Bax JJ, et al. Validation and reproducibility of aortic pulse wave velocity as assessed with velocity-encoded MRI. J Magn Reson Imaging 2009;30:521-6.

[20] Shahzad R, Shankar A, Amier R, Nijveldt R, Westenberg JJM, de Roos A, et al. Quantification of aortic pulse wave velocity from a population based cohort: a fully automatic method. J Cardiovasc Magn Reson 2019;21:27. 